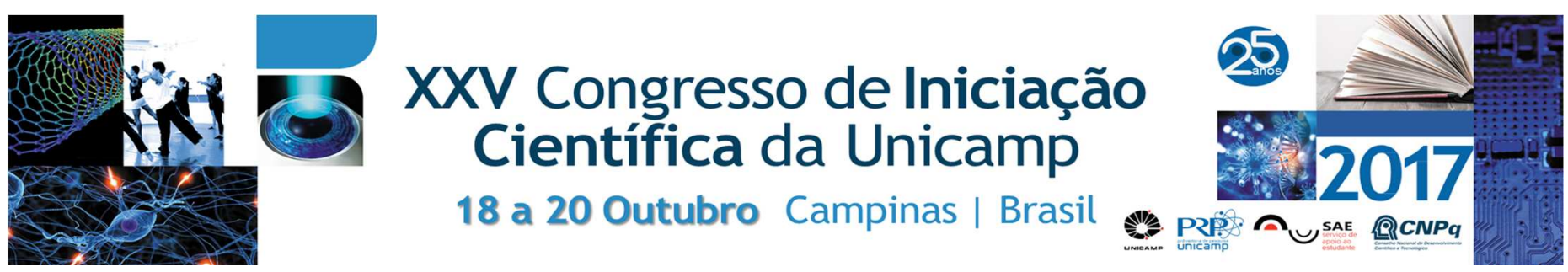

\title{
Tabuleiro de Xadrez Controlado por Eletroimã e por Aplicativo de Celular
}

\author{
José R. Neto; Matheus D. S. Galvão; Luana M. Siqueira; João V. V. D’Abreu.
}

\section{Resumo:}

O projeto destina-se a na implementação de um tabuleiro de xadrez, com base na ideia de um plotter XY que possibilita a movimentação de peças, no modo real, por meio de um eletroímã, e no modo virtual por meio de comandos via um aplicativo de celular. $O$ objetivo do projeto é diversificar a forma como se joga o xadrez e paralelamente aprender conceitos de movimento de objetos no plano XY.

\section{Palavras-chave:}

Robótica Pedagógica, Estrutura XY, Jogo de Xadrez

\section{Introdução}

Hodiernamente uma das principais dificuldades encontradas no ensino de crianças e adolescentes encontra-se na possibilidade de conciliar a vida dinâmica na qual estão inseridas com a rotina de conteúdos estáticos que lhes são submetidas. Pensando nisto objetivou-se projetar uma estrutura, no plano (XY), composta por dois eixos móveis, capaz de levar a estes estudantes a uma experiência imersiva, possibilitando assim a realização de experimentos no plano cartesiano, evolvendo até o uso de smartphone. Além disso, propiciando a concretização de uma cultura "maker" onde os estudantes são protagonistas de seu próprio conhecimento.

Como primeira validação, vislumbrou-se uma partida de xadrez como forma de atrair o interesse do aluno e instigar seu raciocínio lógico. Neste contexto o tabuleiro da Figura 1 é o equipamento a ser utilizado para este fim.

\section{Resultados e Discussão}

O desenvolvimento da estrutura foi baseado em 3 etapas cruciais, mecânica, elétrica e programação. Em cada uma delas obteve-se suas respectivas dificuldades. Por exemplo na parte mecânica o desafio era ter um sistema relativamente preciso que possibilitasse com que os movimentos conjugados dos eixos $X Y$ combinassem com o deslocamento correto de uma peça do tabuleiro de xadrez. A parte elétrica, consistiu na implementação de uma placa Arduino que além de controlar os motores possibilita por meio do microcontrolador gerenciar as 64 posições de um tabuleiro de xadrez, sendo que a realização de um movimento físico de uma peça do tabuleiro automaticamente é detectada e armazenada num computador ou em um dispositivo móvel (smartphone, por exemplo). Do ponto de vista de programação, implementou-se uma estrutura em linguagem Java passível de ser executada em um smartphone Android no qual se exibe uma interface gráfica (representando um tabuleiro de xadrez) e que permite ao estudante realizar partidas tendo como oponente a máquina.

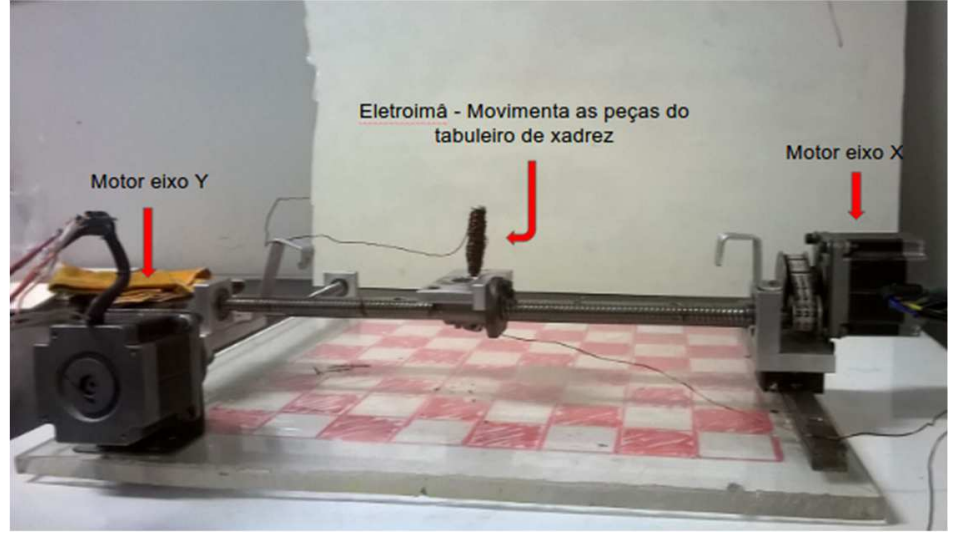

Figura 1. Estrutura de movimento e eletroímã.

\section{Conclusões}

Apesar da invasão tecnológica em nossas vidas, é totalmente possível associar inovações atuais em práticas de lazer antigas como à automatização de jogos de tabuleiros. De fato, isso torna a experiência muito mais agradável e as possibilidades são infinitas. Vislumbra-se com este projeto desenvolver um equipamento que além de possibilitar a prática de movimento de objetos, no plano $X Y$, o uso de smartphone em contexto de sala de aula com propósitos educacionais.

\section{Agradecimentos}

O desenvolvimento do protótipo foi um sucesso, e gostaríamos de agradecer ao NIED (Núcleo de Informática Aplicada à Educação), PRP (Pró-reitora de Pesquisa), PIBIC (Programa Institucional de Bolsas de Iniciação Científica e Tecnológica), UNICAMP, SAE (Serviço de Apoio ao Estudante).

SILVA OLIVEIRA, Edvan. AUMENTANDO AS PORTAS DIGITAIS DO ARDUINO COM CI 74HC595. Disponível em: $<$ http://blogdarobotica.com/aumentando-as-portas-digitais-do-arduino-com-ci74hc595/>. Acesso em: 02 jul. 2017.

THOSEN , Adilson. TUTORIAL MÓDULO BLUETOOTH COM ARDUINO. Disponível em: <http://blog.filipeflop.com/wireless/tutorial-modulo-bluetoothcom-arduino.html>. Acesso em: 02 jul. 2017. 